\title{
La práctica de la iniciativa legislativa en el constitucionalismo español reciente ${ }^{1}$
}

\author{
The recent practice of legislative initiative in spanish constitutional law \\ JOSÉ MARÍA MORALES ARROYO \\ Universidad de Sevilla, España
}

RECEPCIÓN: 17/10/2017 • ACEPTACIÓN: 03/11/2017

RESUMEN: El modelo de democracia que se deriva de la Constitución española aprobada en 1978 se ha intentado definir a través del uso de instrumentos de participación electoral/representativos e instrumentos de participación directa. No obstante, el vértigo de un constituyente timorato, una interpretación restrictiva de la jurisprudencia constitucional y una práctica perezosa han convertido en marginales los instrumentos de participación política semidirecta. Con este complicado marco de partida, el presente trabajo intenta describir los problemas con los que se ha encontrado el reconocimiento constitucional de la iniciativa legislativa popular, valorar cómo se ha gestionado en la vida política ese instrumento de participación ciudadana y, por último, hacer propuestas que pudiesen revitalizar el ejercicio popular de ese mecanismo para que el Cuerpo Electoral pueda colaborar efectivamente en el proceso legislativo junto con las Cortes y el Gobierno.

PALABRAS CLAVE: Modelo democrático - Iniciativa legislativa; - Cuerpo Electoral - Colaboración legislativa.

1. El presente trabajo se ha elaborado en el marco del Proyecto de Investigación denominado Democracia y Participación Política: Hacia una Redefinición de la Ciudadanía Democrática (DER2015-66324-P del Ministerio de Economía y Competitividad del Gobierno de España).

2. Catedrático de Derecho Constitucional, Universidad de Sevilla.email: jmmorales@us.es 
ABSTRACT: The democratic model established in the Spanish Constitution adopted in 1978 has tried to define itself by the use of representational/electoral tools as well as direct political participation. However, the combination of faint-hearted drafting, restrictive interpretation by constitutional jurisprudence and weak practice have marginalized semi-direct political participation. Starting from this complex situation, the objects of the present paper are to describe the issues facing constitutional recognition of the popular legislative initiative, to assess the use of citizen participation as a political instrument, and finally to offer proposals that could reinvigorate the exercise of thismechanism by the people to enable the Electoral College to collaborate effectively with the Cortes (parliament) and the Government in the legislative process.

KEY WORDS: democratic model; legislative initiative; Electoral College; legislative cooperation.

\section{Introducción}

La participación política como base de un Estado democrático e indicador de la calidad de la democracia de un país continúa definiéndose en función a la preponderancia de cada uno de los instrumentos de participación introducido por el texto constitucional en el sistema y la capacidad de implicar a los ciudadanos del Estado para que procedan a su uso. La base mínima para la existencia de un estado constitucional democrático se coloca en la existencia de elecciones periódicas, libres y competitivas que permitan periódicamente, al menos, la renovación y la constitución de un órgano representativo de gobierno. La participación electoral/representativo es el umbral mínimo para que un Estado se incluya en el grupo de los entes democráticos.

No obstante, desde mediados del siglo XX se viene construyendo un axioma constitucional en virtud del cual se considera que la participación electoral no resulta suficiente y, en consecuencia, esa vía para decidir sobre asuntos públicos debe completarse previendo otra serie de mecanismos de participación política que complete, mejore y corrija los defectos del circuito de participación electoral/representativo.

Como en su trabajo clásico ya explicara Aguiar de $\mathrm{Luque}^{3}$, la aceptación de los instrumentos de democracia semidirecta junto con la representación electoral

3. Democracia directa y Derecho Constitucional (Madrid: EDERSA, 1977). 
encontró resistencias en el constitucionalismo por la tensión que los mismos podían añadir al proceso de toma de decisiones por los órganos representativos y por el posible uso fraudulento que de los mismos podían hacer tanto los propios poderes públicos, como los grupos antisistema.

La carga negativa de tales instrumentos llevó al constituyente español, tras asumir el principio democrático en el art. 1 del texto constitucional de 1978 y construir el derecho de participación política como un derecho fundamental de amplio contenido en el art. $23^{4}$, a restringir el número de instrumentos de participación política directa constitucionalizados, al referéndum y a la iniciativa legislativa popular, y, en consecuencia, hacer pivotar todo el proceso decisorio popular sobre unas elecciones periódicas 5 .

La definición doctrinal ortodoxa de nuestro modelo participativo en un contexto democrático es aquella que opta por cohonestar un sistema básicamente articulado a través de elecciones periódicas, libres y competitivas que crean espacios de representación política, con la previsión de instrumentos de democracia semidirecta que mejoran, corrigen y completan el modelo representativo. Y con desconfianza hacia estos últimos:

"Fuera del art. 23 C.E. quedan cualesquiera otros títulos de participación que, configurados como derechos subjetivos o de otro modo, puedan crearse en el ordenamiento (ATC 942/1985), pues no todo derecho de participación es un derecho fundamental (SSTC 212/1993 y 80/1994). Para que la participación regulada en una Ley pueda considerarse como una concreta manifestación del art. 23 C.E. es necesario que se trate de una participación política, es decir, de una manifestación de la soberanía popular, que normalmente se ejerce a través de representantes y que, excepcionalmente, puede ser directamente ejercida por el pueblo, lo que permite concluir que

4. "Los ciudadanos tienen el derecho a participar en los asuntos públicos, directamente o por medio de representantes, libremente elegidos en elecciones periódicas por sufragio universal”.

5. Por referir un conjunto de trabajos en los que se explica "la prudencia" del legislador constitucional y orgánico sobre la cuestión, Pedro Cruz Villalón: "El referéndum consultivo como modelo de racionalización constitucional”, en REP, 13 (1980), pp. 145-168; y Nicolás Pérez Sola: La regulación constitucional del referéndum (Jaén: Universidad de Jaén, 1994), pp. 27 ss. Y sobre la intervención restrictiva del Legislador orgánico en la primera versión de la regulación de la Iniciativa Legislativa Popular en 1984 -algo más de 5 años después de aprobada la Constitución-, se pueden consultar Paloma Biglino Campos: "La iniciativa legislativa popular en el Ordenamiento jurídico estatal”, en REDC, 19 (1987), pp. 114 ss. Y Elviro Aranda: "La nueva Ley de iniciativa legislativa popular", en REDC, 78 (2006), pp. 192 ss. 
tales derechos se circunscriben al ámbito de la legitimación democrática directa del Estado y de las distintas entidades territoriales que lo integran, quedando fuera otros títulos participativos que derivan, bien de otros derechos fundamentales, bien de normas constitucionales de otra naturaleza, o bien, finalmente, de su reconocimiento legislativo" ${ }^{6}$.

La interpretación y la práctica escoradas hacia un modelo de democracia representativa tanto por motivos históricos, como por motivos de eficacia, han colocado en España, de partida, en una posición debilitada a los instrumentos de democracia semidirecta y los han convertido en mecanismos marginales de participación. Esa marginalidad, que se manifiesta en lo limitado de su uso, hace complicada la afirmación de que la experiencia democrática de los ciudadanos españoles se ve mejorada por su reconocimiento constitucional y su práctica.

Una vez que han transcurrido cuatro décadas desde la aprobación de la Constitución, el continuar manteniendo axiomas preventivos frente a los instrumentos de participación política demuestra un miedo injustificado a los procesos democráticos poco compatibles con una cultura política consolidada durante dicho período de tiempo. Lo recordaba Presno Linera recientemente. "Es obvio que hay que situar las reticencias en el contexto de la transición de la dictadura a la democracia, pero también parece evidente que se exageraron los peligros, se desvirtuó su eficacia en el derecho comparado y, desde luego, no se hizo nada después, ya con la democracia ya consolidada, para atribuirles la relevancia que merecen" 7 .

En esa línea de recuperación se tratará la práctica de una de las dos instituciones de democracia directa reconocida a los ciudadanos españoles por la Constitución, la iniciativa legislativa popular. El escaso uso del referéndum consultivo previsto en el art. 92 de la Constitución, dificulta que se pueda construir una dogmática sobre las consultas populares en nuestra experiencia reciente ${ }^{8}$. En cambio, sobre la

6. STC 119/1995, FJ 3. "Y aún si se admitiera que la Ley puede ampliar los casos de participación directa, los supuestos habrían de ser, en todo caso, excepcionales en un régimen de democracia representativa como el instaurado por nuestra Constitución, en el que "priman los mecanismos de democracia representativa sobre los de participación directa»" (STC 76/1994, F J 3).

7. En "La democracia participativa como instrumento de impulso, deliberación y control", en José Luis Cascajo y Augusto de la Vega (coord.): Participación, representación y democracia (Valencia: Tirant lo Blanc, 2016), pp. 194.

8. El Referéndum de 12 de marzo de 1986, sobre la permanencia del Reino de España en la OTAN, y el Referéndum de 20 de febrero de 2005 sobre la aprobación del Tratado que establece una Constitución para la Unión Europea. 
iniciativa legislativa popular, aunque han sido escasos los texto aprobados a partir de la acción ciudadana ${ }^{9}$, la experiencia normadora y la práctica consecuencia de su uso nos permiten valorar en qué lugar se localizan sus defectos de diseño, cómo ha sido utilizado en algo menos de tres décadas y proponer vías para su mejora.

\section{La iniciativa legislativa popular como mecanismo de participación política}

La Constitución española, como resulta conocido, ha optado por una versión bastante restringida de iniciativa popular en su art. 87.3, entendida como una propuesta sobre una cuestión política que se traslada formalmente desde el Cuerpo Electoral a las instituciones representativas. En el caso español, el reconocimiento alcanza tan solo a iniciativas en el campo de la legislación ordinaria y excluye de su contenido regulatorio un catálogo importante de materias. Asimismo, de un lado, concede al Cuerpo Electoral capacidad para poner en marcha el proceso legislativo, pero no para expulsar una norma del ordenamiento a través de un proceso derogatorio. De otro lado, separa la iniciativa legislativa del otro mecanismo de participación, el referéndum consultivo, de manera que los ciudadanos ven negada la posibilidad de llevar ante los poderes públicos la necesidad de realizar una consulta sobre un tema político trascendente y, en consecuencia, quedando a la entera disposición de estos su convocatoria.

La reflexión debe completarse desde una perspectiva política, valorando el hecho de que en el ejercicio de las facultades de iniciativa el Cuerpo Electoral entra en competencia con el Gobierno y las Cámaras de las Cortes Generales (art. 87.1) y, en menor medida, con las instituciones de las Comunidades Autónomas (art. 87.2). Los ciudadanos con su iniciativa intentan colocar en la agenda política y legislativa el debate y, eventualmente, la aprobación de un texto legislativo que no emana de las instituciones encargadas del ejercicio de la facultad de dirigir políticamente el Estado. En consecuencia, la receptibilidad de esa vía de colaboración ciudadana no solicitada en tareas legislativas va a encontrarse mediatizada por circunstancias de naturaleza política coyuntural y por la cultura democrática que se haya ido construyendo políticamente. En ese entramado, la iniciativa legislativa popular

9. A partir de iniciativas ciudadanas se han aprobado la Ley 8/1999, de reforma de la Ley 49/1960, sobre propiedad horizontal; la Ley 18/2013, de regulación de la tauromaquia como patrimonio cultural; y, solo parcialmente, la Ley 1/2013, de refuerzo de los deudores hipotecarios, reestructuración de la deuda y vivienda social. 
(ILP, desde ahora) puede concebirse como un instrumento de colaboración entre ciudadanos y órganos constitucionales, o bien catalogarse beligerantemente como un mecanismo de intromisión y alteración de los programas de gobierno.

La reducción de la iniciativa popular al estricto ámbito legislativo y el hecho de que no pueda utilizarse como una vía para imponer asuntos de interés en el debate público sin una predeterminación en el contenido de una futura normación, puede considerarse por sí mismo un motivo relevante para comprender la escasa receptibilidad de Gobierno y de Cortes Generales hacia tales iniciativas. La propuesta ciudadana de regulación de una determinada realidad social presentada a través de un texto articulado porta en su interior una preconcepción política que puede chocar con el programa de gobierno y su agenda, así como con la composición política de cada Cámara legislativa. A veces a los ciudadanos solo les puede interesar colocar un tema en el debate público y dejar a los titulares del circuito representativo que definan el contenido de su solución; pero en nuestro caso, esa es una opción que queda al margen de esta facultad de participación política.

Estas y otras circunstancias condicionan el análisis de la materia, mientras que esta última reflexión nos lleva inexorablemente a una reforma del mencionado párrafo $3^{\circ}$ del art. $87^{10}$. Por lo tanto, a continuación, en primer lugar, se hará referencia al tema conocido de la regulación de la institución en nuestro ordenamiento, para, con posterioridad, desplazar la exposición hacia cuestiones como las pautas que se han seguida en su utilización práctica en los años posteriores a su puesta en marcha o su eficacia. Por último, se tratará de cerrar la exposición con una reflexión sobre los elementos de naturaleza normativa que vienen lastrando su utilización y las vías más razonables para su futura solución.

\subsection{Los rasgos de la regulación constitucional y la intervención del legislador ordinario}

La institución de la iniciativa legislativa popular se introduce en nuestro ordenamiento a través de su reconocimiento constitucional, la conocida atribución de

10. No obstante, sin reformar el texto constitucional, debiera someterse a observación y seguimiento el camino que actualmente está abriendo el Parlamento Británico en el que se ha creado mediante una vía directa y telemática la posibilidad de que los ciudadanos lleven temas de debate a la Cámara de los Comunes a través de la Comisión de Peticiones; $c f r$. nuestro trabajo "Una reforma conectada con el derecho de participación política”, en G. Ruiz-Rico Ruiz, A. Porras y M. Revenga (coord.): Regeneración democrática y reforma constitucional (Valencia: Tirant lo Blanch y Centro de Estudios Sociales y Jurídicos del Sur de Europa, 2017), especialmente pp. 209-210. 
competencias para poner en marcha el procedimiento legislativo del art. 87.3. Un precepto que apenas reconoce al Cuerpo Electoral la facultad de presentar iniciativas de naturaleza legislativa, requiriendo el apoyo de la voluntad de quinientos mil electores, fija un listado incompleto de materias excluidas, y remite el grueso de su regulación a la posterior intervención del Legislador orgánico ${ }^{11}$. Por lo tanto la capacidad del legislador a la hora de configurar el procedimiento de presentación y tramitación de estas iniciativas era muy amplio, pues lindaba solo con la garantía del derecho individual del participación política del art. 23 de la CE y con el respeto de las condiciones fijadas en el art. 87.3 y otros concordantes de la propia Constitución.

No es misión de este trabajo reiterar cuestiones que la doctrina española de Derecho público ha estudiado sobradamente ${ }^{12}$, por lo que nos centraremos en recordar aquellos temas que a los fines de este trabajo poseen una mayor relevancia.

La iniciativa debe venir impulsada por un comisión promotora integrada por electores, se presenta como un texto articulado, en el control de su contenido participa el Congreso de los Diputados y, excepcionalmente, el Tribunal Constitucional, la corrección del proceso de recogida de firmas y el recuento de las mismas están asegurados por la Junta Electoral Central y, una vez confirmado el número mínimo de las quinientas mil firmas de electores, se establece un plazo máximo de 6 meses para el inicio de su tramitación parlamentaria.

11. "Una ley orgánica regulará las formas de ejercicio y requisitos de la iniciativa popular para la presentación de proposiciones de ley. En todo caso se exigirán no menos de 500.000 firmas acreditadas. No procederá dicha iniciativa en materias propias de ley orgánica, tributarias o de carácter internacional, ni en lo relativo a la prerrogativa de gracia”. El desarrollo del precepto constitucional se hizo a través de la Ley Orgánica 3/1984, de 26 de marzo, reguladora de la iniciativa legislativa popular, profundamente modificada a través de la LO 4/2006, de 26 de mayo. Resulta de interés para conocer cómo se produjo en su día la intervención restrictiva del Legislador orgánico en la primera versión de la regulación de la Iniciativa Legislativa Popular en 1984 -algo más de 5 años después de aprobada la Constitución-, se pueden consultar Paloma Biglino Campos: "La iniciativa legislativa popular en el Ordenamiento jurídico estatal”, en REDC, 19 (1987), pp. 114 ss. Y Elviro Aranda: "La nueva Ley de iniciativa legislativa popular”, en REDC, 78 (2006), pp. 192 ss.

12. Por citar algunos trabajos más recientes y de interés sobre la institución, se pueden recomendar Miguel Ángel Fernández Ferrero: La iniciativa legislativa popular (Madrid: CEPC, 2001); Víctor Cuesta López: Participación directa e iniciativa legislativa del ciudadano en democracia constitucional (Madrid: Thomson/Civitas, 2008); David Almagro Castro: “¿Qué iniciativa legislativa popular tenemos? ¿Qué iniciativa legislativa popular necesitamos? El art. 87.3 CE y la LOILP 4/2006 a debate", en RGDC, 22 (2016); y Joaquín J Marco Marco: "La iniciativa legislativa popular en España (o el mito de Sísifo)”, en RGDC, 8 (2009) . 
Además del número mínimo de apoyos que requiere la viabilidad de la iniciativa, la Constitución enumera un cúmulo heterogéneo de materias o, más bien, de áreas materiales-funcionales en las que se encuentra vedado el uso de la ILP. En consecuencia, quedan excluidas de esta modalidad de iniciativa las materias propias de Ley Orgánica, las materias tributarias, las materias de naturaleza internacional y las cuestiones relativas a las decisiones sobre la prerrogativa de gracia (art. 87.3 CE).

A estas materias se añaden a lo largo del texto constitucional, como parcialmente recuerda el apartado $5^{\circ}$, del art. 2 de la LO 3/1984, otras que también se excluyen del objeto de la iniciativa. La planificación económica (art. $131 \mathrm{CE}$ ) y la capacidad para presentar proposiciones de ley de presupuesto (art. 134.1 CE) son de exclusiva iniciativa gubernamental; por lo tanto, ni los ciudadanos ni el resto de los actores mencionados en el art. 87 se encuentran habilitados para sustituir la decisión del Gobierno de ponerlos en marcha. A ello se añade la iniciativa de reforma constitucional en virtud a que el reenvío establecido en el art. 166 de la CE excluye al Cuerpo Electoral de entre los habilitados para proponer un texto de reforma.

Con posterioridad se regresará al tema de los ámbitos materiales excluidos de la ILP y su coherencia con el principio democrático del art. 1 y el derecho de participación política del art. 23, ambos de la Constitución. A priori, no se discute su regularidad porque la excepción se incluye en el propio texto constitucional, aunque el respeto al reconocimiento del derecho fundamental de participación política hubiera sugerido una interpretación restrictiva de la eficacia de los límites materiales.

Como de lo expuesto se puede comprender, las restricciones al ejercicio de la facultad de presentar ILP pueden provenir de la propia regulación constitucional o de la concreción que realiza el legislador orgánico de los cánones constitucionales, además de otros factores ambientales como la escasa politización de la sociedad o el entendimiento de los electores que el uso de la institución resulta inadecuado porque conforme a la experiencia la iniciativas tienen escasas probabilidades de prosperar.

Por lo tanto, una comprensión de los problemas que afectan a las ILP requiere una revisión de la práctica seguida hasta el momento para con ello desvelar el nivel de la implicación que los ciudadanos individual o colegiadamente tienen en la promoción y el apoyo a las iniciativas populares. 


\subsection{Las evidencias sobre la utilización de las iniciativas legislativas populares}

El análisis de la práctica de esta institución no puede quedar en la constatación de los magros resultados que suponen las tres leyes aprobadas a día de hoy, que tuvieron su origen total o parcial en una inicial proposición ciudadana.

La compresión del fenómeno legislativo en su conjunto precisa partir de la aceptación de la realidad que supone la premisa de que el núcleo central de las leyes que se aprueban en los Estados contemporáneos, especialmente en aquellos de preponderancia parlamentaria, se localiza en propuestas de origen gubernamental. El Gobierno impone a través de la agenda legislativa qué textos se aprueban, con qué orientación normadora y en qué momento se presentan y aprueban. En el sistema político español, la propia Constitución privilegia la tramitación de los textos legislativos gubernamentales frente al resto ${ }^{13}$. Por lo tanto, la previsión y la realidad hacen que sean esporádicos los textos normativos procedentes de autores distintos al Gobierno con capacidad de iniciativa que se presentan y terminan superando la barrera de la mayoría, hasta convertirse en leyes vigentes. Las leyes parlamentarias (con origen en el Congreso de los Diputados o el Senado), las leyes autonómicas (con origen en una proposición de un parlamento territorial) y las leyes de origen ciudadano componen un corpus normativo claramente complementario del derecho de origen gubernamental. Esa realidad se alimenta y termina extendiendo una cierta convicción sobre que alterar o invertir ese estatus puede ser perturbador para el funcionamiento del sistema político, ya que debilita en la práctica el principio constitucional de que al Gobierno corresponde la dirección política del Estado (art. $97 \mathrm{CE}$ ).

Pese al férreo control gubernamental, el panorama para las leyes de iniciativa ciudadana no es muy prometedor. Se puede aceptar como paradigma que un exceso de normas de este tipo puede distorsionar el circuito representativo. Si llegan a multiplicarse de manera considerable las iniciativas que se promueven desde la ciudadanía, se podrían desestabilizar algunas parcelas del sistema político-constitucional porque sería la prueba evidente de la existencia de una importante y continuada tensión o divorcio entre los órganos representativos del Estado y el Cuerpo Electoral. Con el agravante de que si los representantes electos de manera habitual no tramitasen o rechazaran las iniciativas ciudadanas se terminaría produciendo no solo una fractura

13. Al respecto, Piedad García-Escudero: La iniciativa legislativa del Gobierno (Madrid: CEPC, 2000). 
en la representación, sino un claro episodio de frustración social o de desinterés por un instrumento participativo carente de efectividad.

Pues bien, entre el difícil equilibrio de lo mucho y lo poco ¿cómo se han comportado las instituciones representativas ante el fenómeno de las iniciativas legislativas ciudadanas y cómo las han usado sus titulares?

Para ello basta con revisar los datos que se recogen en la siguiente tabla sobre las vicisitudes arrostradas por las iniciativas que hasta fecha reciente se han tramitado.

Iniciativas Legislativas Populares

\begin{tabular}{|c|c|c|c|c|c|c|c|c|c|c|c|c|}
\hline & $\begin{array}{c}\text { II } \\
82 / 86\end{array}$ & $\begin{array}{c}\text { III } \\
86 / 89\end{array}$ & $\begin{array}{c}\text { IV } \\
89 / 93\end{array}$ & $\begin{array}{c}\mathrm{V} \\
93 / 96\end{array}$ & $\begin{array}{c}\text { VI } \\
96 / 00\end{array}$ & $\begin{array}{c}\text { VII } \\
00 / 04\end{array}$ & $\begin{array}{c}\text { VIII } \\
04 / 08\end{array}$ & $\begin{array}{c}\text { IX } \\
08 / 11\end{array}$ & $\begin{array}{c}X \\
11 / 15\end{array}$ & $\begin{array}{c}\text { XI } \\
15 / 16\end{array}$ & $\begin{array}{l}\text { XII } \\
16 /-\end{array}$ & Total \\
\hline Rechazadas & & & & & 3 & 4 & 1 & & 2 & & & 10 \\
\hline Caducadas & & 1 & 4 & 1 & 2 & 3 & 7 & 6 & 13 & 1 & & 38 \\
\hline Inadmitidas & 3 & & 2 & 3 & 1 & 3 & 3 & 8 & 14 & & 1 & 38 \\
\hline Trasladadas & & 1 & & 2 & 4 & 3 & 2 & 7 & 4 & 5 & & 28 \\
\hline Retiradas & & & 1 & & & & & 2 & 1 & & & 4 \\
\hline Aprobadas & & & & & & & & & 1 & & & 1 \\
\hline $\begin{array}{l}\text { Tramitadas } \\
\text { sin acuerdo }\end{array}$ & & & & & & & & & 1 & 1 & & 2 \\
\hline Subsumidas & & & & & 1 & & & & 1 & & & 2 \\
\hline $\begin{array}{l}\text { Presentadas/ } \\
\text { Calificadas }\end{array}$ & & & & & & & & & & & 9* & 9 \\
\hline Total & 3 & 2 & 7 & 6 & 11 & 13 & 13 & 23 & 37 & 7 & 10 & 132 \\
\hline
\end{tabular}

Fuente: Elaboración propia a partir de los datos extraídos de la página Web del Congreso de los Diputados (www.congreso.es, Datos consultados hasta julio de 2017).

* 1 en tramitación.

La depuración de los datos de la Tabla dan un pobre resultado de 104 ILP presentadas desde la II Legislatura, mandato en el que se aprueba la LO 3/1984 y se pueden comenzar a tramitar regularmente ${ }^{14}$. Parece que hay una cierta mejoría tras la importante reforma legislativa de 2006 que suavizaba las condiciones de

14. Desde el año 1982 se han presentado 104 Iniciativas populares y se han aprobado 3. Para dimensionar ese dato, basta conocer que desde ese mismo año entre leyes orgánicas y ordinarias se han aprobado 1.575 disposiciones por las Cortes Generales, y el Gobierno ha aprobado 430 decretos-leyes y 64 Decretos legislativos. 
la tramitación; aunque el factor normativo no es el único a tener en cuenta en el análisis de tales datos. De ese número, 48 fueron rechazadas por el Congreso, bien por inadmisión (10), bien porque no pasaron el trámite de toma en consideración (38), lo que supone un importante 46,15 por ciento. También resulta alto el número de caducadas (38), bien por inacción parlamentaria, bien por incapacidad de los promotores para cumplir los plazos legales, normalmente en el proceso de recolección de firmas. El resto, salvo 3 (1 aprobada sin cuestionamiento y las otras 2 subsumidas en nuevos textos), ha vivido diferentes peripecias procedimentales.

Si de los estrictos números nos trasladamos a comprobar las razones que han motivado el rechazo de ciertas iniciativas populares que han llegado al trámite de toma en consideración, y no lo superaron, durante la VIII Legislatura (2004-2008), la IX Legislatura (2008-2011) y la X Legislatura (2011-2016), se identifican varias pautas coincidentes.

La primera, que suele ser la oposición la que asume la defensa de las iniciativas populares que llegan al Pleno del Congreso de los Diputados con la intención de colocar en apuros a la mayoría gubernamental. Así ocurre cuando los diputados populares asumen la defensa de una iniciativa dirigida a modificar el Código Civil en materia de matrimonio y adopción ${ }^{15}$ o cuando los diputados socialistas defendieron la Proposición de Ley de la Televisión sin fronteras ${ }^{16}$ y la Proposición de Ley para el empleo estable y con derechos ${ }^{17}$. Resultaba indiferente si en la defensa coincidían o no con la filosofía de la norma tramitada. La acción parlamentaria se podía considerar de "bajo riesgo", en la medida que se conocía de antemano la posición de rechazo de la mayoría hacia la iniciativa. El premio, en cambio, suponía el sometimiento de la mayoría gubernamental a un debate que no deseaba y a una votación en la que se verificaría un rechazo de una propuesta avalada por cientos de miles de electores.

Y, segundo, la mayoría suele repeler las iniciativas cuando no se ajustan a los elementos propios de su programa de gobierno o no mejoran su posición ante la opinión pública, lo que indirectamente supondría conceder un triunfo a la oposición que ha hecho suya la iniciativa popular ${ }^{18}$. En los tres supuestos en los

15. DSCD, Pleno y Diputación Permanente, núm. 235, de 27 de febrero de 2007, pp. 11806 y ss. 16. DSCD, Pleno y Diputación Permanente, núm. 51, de 11 de septiembre de 2011, pp. 6 y ss.

17. DSCD, Pleno y Diputación Permanente, núm. 75, de 11 de diciembre de 2012, pp. 6 y ss.

18. DSCD, Pleno y Diputación Permanente, núm. 235, cit., pp. 11815 y ss.; DSCD, Pleno y Diputación Permanente, núm. 51, cit., pp. 17 y ss.; y DSCD, Pleno y Diputación Permanente, núm. 75, cit., pp. 18-20. 
que se ha aprobado un texto de iniciativa popular, en dos de ellos se trataba de un tema neutral, no previsto en el programa de gobierno; pero, que la mayoría acepta regular conforme a la propuesta ciudadana porque le concede ventajas entre en el electorado ${ }^{19}$. Mientras que en el tercero de los textos, y pese a que el Gobierno contaba con mayoría absoluta en ambas Cámaras legislativas, la iniciativa se acepta inicialmente como una imposición de la que se pueden posteriormente obtener réditos políticos ${ }^{20}$.

Por último, la ley que se aprueba en 1999 se elaboró en un contexto en el que el Gobierno contaba con mayoría relativa, lo que hizo necesario el consenso entre diversas fuerzas parlamentarias tanto para la toma en consideración como la aprobación del texto de la iniciativa popular. Los que la apoyaron entendieron que la asunción de la iniciativa popular mejoraba su posición entre la opinión pública.

\subsection{El rediseño normativo de la institución de participación}

El corto listado de iniciativas presentadas y apoyadas no representa un número de tal envergadura como para que se produzca una quiebra en nuestro parlamentarismo, ni, por supuesto, para que se bloquee o ponga en riesgo el circuito electoral/ representativo de participación.

No solo la preponderancia gubernamental en el control de la agenda legislativa puede justificar el escaso uso que se ha hecho de este instrumento complementario de participación política. Con tan bajos datos se puede cuestionar su utilidad; difícilmente se puede mantener que resulta un instrumento útil para acercar a los poderes públicos el interés serio de la ciudadanía porque se regulen ciertas materias de una forma determinada y con ello se entienda que el Cuerpo Electoral colabora activamente en el proceso de construcción de la agenda legislativa más allá de su pronunciamiento en las elecciones parlamentarias.

A ello deben añadirse las dificultades intrínsecas de la propia institución para alcanzar sus objetivos; como, por ejemplo, el tiempo que transcurre entre la creación de la comisión promotora de una iniciativa, su presentación, la recogida de firmas, el recuento y la tramitación parlamentaria, y el momento definitivo de

19. Así ha sucedido con la reforma de la Ley de Propiedad horizontal de 1999 y con la regulación de la Tauromaquia como patrimonio cultural en 2013.

20. Sobre la tramitación de la Ley 1/2013, cfr. Alicia Agüero: "Proyecto de Ley de Medidas Urgentes para reforzar la protección a los deudores hipotecarios”, en Revista CESCO de Derecho al Consumo, 5 (2013), pp. 262-272. 
la aprobación del texto legislativo de origen popular. El tiempo además de moldear la capacidad de respuesta de las instituciones puede terminar por considerarse un elemento añadido a la frustración del Cuerpo Electoral, que puede organizada o desorganizadamente recurrir a vías más rápidas, efectivas y menos transparentes, como el lobbismo, para incidir en el proceso y en los resultados legislativos.

Ante esta realidad cada vez se hace más conveniente el cuestionarse si no se pueden arbitrar medidas que mejoren y faciliten los procesos de presentación de ILP y saquen a la institución de lo anecdótico. Las propuestas de reforma que se pueden poner sobre la mesa van en la línea de modificar el texto de la Constitución, en la medida que la revisión de la LO 3/1984 realizada en el año 2006 corrigió varias disfunciones que actuaban como un obstáculo a la hora de permitir la presentación y tramitación de iniciativas ciudadanas ${ }^{21}$.

En clave política, no puede olvidarse que la presentación de una iniciativa legislativa popular supone un esfuerzo político y técnico para sus promotores. Por lo tanto, ese esfuerzo debe compensar por su resultado y el cauce procedimental no debe desincentivar a la opinión pública añadiendo dificultades a la decisión de impulsarla y a la participación de los ciudadanos en el proceso de recolección de firmas de apoyo. Así pues, las normas que las regulen no deben impedir o dificultar gravemente el proceso participativo. En esa línea iban las reformas constitucionales frustradas en la X Legislatura y la aún pendiente de toma en consideración proveniente de la Junta General del Principado de Asturias ${ }^{22}$.

21. Entre las más significativas, la desaparición de algunas causas de inadmisión de dudosa constitucionalidad que aumentaban las discrecionalidad de la Mesa del Congreso de los Diputados a la hora de admitir o inadmitir las proposiciones, el aumento de 6 a 9 meses el período de tiempo fijado para la obtención de las firmas de apoyo a la propuesta y la posibilidad de recurrir a vías telemáticas para la captación de firmas.

22. Las propuestas para mejorar la participación ciudadana aumentando la calidad democrática se han configurado a través de iniciativas de reforma constitucional. En la X Legislatura se presentó por las fuerzas minoritarias de izquierda un texto de reforma constitucional "para reforzar la participación política y el pluralismo en el régimen electoral"; una se presentó el 31 de enero de 2012 y se formalizó su retirada el 14 de mayo de 2013 (el texto se localiza en BOCG, Congreso de los Diputados, B-55-1, de 10 de febrero de 2012; mientras que el acuerdo de retirada se localiza en BOCG, Congreso de los Diputados, B-55-2, de 20 de mayo de 2012) y un texto similar se presentó por las mismas fuerzas el 13 de mayo de 2013 y caducó con la disolución de la Cámara y el fin de la Legislatura (texto en BOCG, Congreso de los Diputados, B-122-1, de 24 de mayo de 2013; y la declaración de caducidad en BOCG, Congreso de los Diputados, D-758, de 20 de noviembre de 2015). Actualmente se encuentra en tramitación otra reforma de los arts. 87.3, 9 y 166 de la Constitución iniciada desde la Junta General del Principado de Asturias el 16 de octubre de 2014, trasladada de una Legislatura a otra y, a día de hoy, pendiente del trámite de toma en 
En el marco de las propuestas partidistas, durante las pasadas campañas electorales, el partido Ciudadanos planteó la posibilidad de mejorar la dinámica de la ILP mediante la reducción a la mitad del número de firmas de votantes exigidas para que prospere la propuesta de ley. Desde su perspectiva, la rebaja facilitaría el proceso de recopilación de apoyos y multiplicaría el número de iniciativas. Pero, el número de firmas actualmente requerido por el art. 87.3 no se puede considerar excesivo; de hecho supone el 1,47 por ciento del censo electoral usado para las últimas elecciones del 26 de junio de 2016 (35.001.447 electores en total). Esta cifra debe considerarse desde una perspectiva distinta; qué propuesta legislativa se puede considerar seria si apenas concita alrededor el apoyo de quinientos mil ciudadanos. Ese número de firmas confirma que en el marco de la opinión pública existe una minoría suficiente para requerir una decisión legislativa del Gobierno y las Cortes Generales; cuanto mayor sea el apoyo ciudadano mayor es la responsabilidad del Congreso de los Diputados en el momento de decidir su tramitación y más meditado debe ser el proceso de enmienda y de cambio del texto original durante los diferentes pasos del procedimiento legislativo.

El problema real de la dificultad para que prosperen las ILP se encuentra en el conjunto de las materias constitucionalmente excluidas ${ }^{23}$. Es decir, los ciudadanos deben interesarse por una proposición de ley sobre una realidad social que no afecte a materias propias de Ley Orgánica, sin implicaciones presupuestarias, ni relevancia para las relaciones internacionales, que sea de interés suficiente como para que una Comisión Promotora de ciudadanos se ponga en marcha, comience los trámites y consiga quinientos mil apoyos de votantes en menos de 9 meses. La empresa resulta complicada y el panorama desmotivador.

Si se repasa con una perspectiva propia de un modelo democrático consolidado, las materias excluidas del campo de la regulación de las ILP se deben abrir nuevas vías para su valoración. Una interpretación extensiva de las materias de Ley Orgánica (art. 81 de la CE) apenas deja campo de interés para la búsqueda de espacios regulatorios. Si los riesgos que se continúan enumerando para mantener esta excepción son los habituales -evitar un aumento que ponga en riesgo la legitimidad

consideración (Texto en BOCG, Congreso de los Diputados, B-1-1, de 9 de septiembre de 2016).

23. De hecho en la propuesta de reforma constitucional de mayo de 2013 el catálogo de materias excluidas desaparecía; mientras que en la propuesta de reforma de la Junta General del Principado de Asturias, las materias se reducen a aquellas en las que el elemento demagógico puede primar: "No procederá dicha iniciativa para la aprobación o modificación de la Ley de Presupuestos Generales del Estado, ni en materias tributarias o de carácter internacional, ni en lo relativo a la prerrogativa de gracia" (Nueva redacción propuesta para el apart. $3^{\circ}$ del art. 87.3 CE por el art. 1 de la propuesta de reforma). 
parlamentaria y desmotive a la ciudadanía (desafectación), la demagogia, la falta de conocimientos en asuntos legislativos, el que existen parecidas exclusiones en otros ordenamientos, etc.-; a estas alturas se estarían manteniendo prejuicios frente a la madurez del comportamiento de la ciudadanía que quizás se pudiesen airear durante las Constituyentes, pero que a día de hoy dejan translucir una fuerte desconfianza hacia el sistema democrático. Sobre todo si se piensa que la última palabra pertenece al Congreso de los Diputados que puede decidir la no toma en consideración y, en caso contrario, en la capacidad de las Cortes Generales para la enmienda del texto originario durante la tramitación parlamentaria en defensa de intereses generales.

Algo parecido ocurre con las materias internacionales, donde los argumentos concurrentes en la doctrina suelen consistir en premisas como que se encuentran excluidos en otros modelos constitucionales para la institución de la ILP, que los temas de relaciones internacionales son delicados por las responsabilidades exteriores del Estado o que la complejidad de los mismos complican la recta apreciación de los ciudadanos. A este respecto no deja de ser irónico que en las dos únicas ocasiones en las que se ha llamado en convocatoria de referéndum consultivo a los ciudadanos españoles haya sido para pronunciarse positiva o negativamente sobre delicados temas de política internacional, la permanencia en la OTAN en 1986 y la ratificación por España del Tratado Constitucional de la UE en 2005. La dificultad de las ILP en materia internacional, más que nada, proviene de su carácter legislativo; no se puede utilizar una iniciativa popular, por ejemplo, para romper relaciones diplomáticas con otro Estado, porque requieren que se sustancien a través de un texto articulado, y ello solo sería viable para modificar un tratado internacional. En este caso, entran en juego otras dos reglas constitucionales, que la dirección de la política internacional pertenece al Gobierno (art. $97 \mathrm{CE}$ ), bajo control de las Cortes (art. $66 \mathrm{CE}$ ), y que los tratados con su especial fuerza pasiva, solo se pueden modificar por el procedimiento que se siguió para su aprobación o conforme a las reglas sobre tratados admitidas en el marco internacional (art. $96 \mathrm{CE}$ ).

Por último, quizás la excepción más sangrante es la que se deriva de la exclusión de este tipo de iniciativa en el caso de la reforma constitucional, a tenor del mandato del art. 166 CE. El mantenimiento del Cuerpo Electoral fuera de la capacidad para articular una iniciativa de la reforma constitucional sobre argumentos del riesgo que supone un uso demagógico de la facultad por los ciudadanos rezuma acudiendo a la idea del "riesgo", como recordaba PRESNO, una posición de miedo a la democracia ${ }^{24}$.

24. En "La democracia participativa como instrumento de impulso, deliberación y control", cit., pp. 194 ss. 
Además, por un lado, la sociedad española de 2017 no es la de 1978 en lo que se refiere a la experiencia y convivencia sobre patrones democráticos. Si se continúa temiendo que se produzca un abuso de la facultad, se pueden establecer condiciones especiales que eviten el uso de la iniciativa en procesos marcados por un contexto demagógico; quizás exigiendo un número más alto de firmas que demuestren la seriedad de la corriente favorable a la reforma constitucional en el Cuerpo Electoral, o bien limitada la posibilidad de reforma al ámbito del procedimiento ordinario del art. $167 \mathrm{CE}$ o en todo caso convirtiendo en preceptivo el referéndum de ratificación para las reformas iniciadas por los ciudadanos. De hecho, los reglamentos de Congreso y Senado exigen un mayor apoyo de grupos y parlamentarios cuando se trata de iniciar la reforma constitucional ${ }^{25}$.

Y, por otro lado, los abusos tienen distintos momentos de corrección a lo largo del proceso de reforma constitucional: en el acto de toma en consideración por el Congreso de los Diputados, con la introducción de enmiendas al texto originario, la superación de mayorías cualificadas que se articulan en diversas lecturas y, eventual o preceptivamente, una ratificación mediante la convocatoria para su aceptación por todo el Cuerpo Electoral en referéndum.

La existencia de esta posibilidad hubiera constituido una válvula de seguridad que hubiese hecho enfrentarse a las fuerzas políticas españolas a las necesarias reformas de la Constitución y, quizás con ello, se hubiese superado el bloqueo institucional que viene arrastrando nuestro sistema político en torno al tema de la reforma de una manera más intensa durante esta última década.

Por lo tanto, en 2017 resulta cuestionable la distancia entre el reconocimiento de la participación semidirecta de los ciudadanos en asuntos públicos y el mantenimiento en el supuesto de la ILP de una regulación constitucional tan restrictiva, hasta el extremo de que por mucho esfuerzo que realice el legislador de desarrollo, convierte en impracticable o inapreciable su uso ${ }^{26}$. Una relajación de las condiciones

25. En el Congreso la iniciativa legislativa ordinaria es facultad de 15 diputados o de un grupo parlamentario (art. 126.1 de su Reglamento) y la de reforma constitucional debe ser presentada con el apoyo de $1 / 5$ de los diputados o de 2 grupos parlamentarios (art. 146.1 de su Reglamento). En el Senado se requiere para la primera que las proposiciones vengan suscritas por un grupo parlamentario o 25 senadores (art. 108.1 del Reglamento del Senado) y para las reformas constitucionales por 50 senadores que no pertenezcan a un mismo grupo parlamentario (art. 152 de su Reglamento).

26. Incluso en las materias de naturaleza tributaria se aprecia un giro esperanzador desde la respuesta dada por los AATC 26 y 592 de 1985, en los que se consideraba constitucional la inadmisión por el Congreso a sendas propuestas dirigidas a crear una prestación de jubilación 
en el sentido aquí mantenido dinamizaría el uso de esta institución participativa, ofreciendo un diálogo entre el órgano legislativo, las Cortes, y el Cuerpo Electoral, en el que tanto interés tendrían las propuestas de creación legislativa, como aquellas otras dirigidas a derogar o abrogar textos normativos con rango de ley.

Ahora que parece se abre un momento de reforma del texto constitucional habrá, entre otras cosas, que decidir qué modelo de participación política se desea consolidar para conseguir un mayor grado de legitimación del sistema político a través del funcionamiento de un modelo democrático más completa y de mejor calidad. Si se desea avanzar en un modelo más ecuánime, conforme al enunciado del art. 23 de la Constitución, se debe proceder a reequilibrar la participación electoral/representativa y la participación directa, ello debe conducir a una reducción de los límites normativos, constitucionales y legales, y la capacidad de veto de las instituciones representativas y a un aumento de la capacidad de acción de los ciudadanos, con el convencimiento de que siempre estos artefactos participativos serán complementarios y no sustitutos de la representación de origen electoral.

Cualquier otra opción, dará lugar al sostenimiento de un status quo en el que la participación política directa continuará siendo anecdótica y observada con desconfianza por las fuerzas políticas consolidadas en los órganos representativos. No se debe olvidar que un mal funcionamiento de los mecanismos de participación política directa se puede considerar síntoma de una realidad en la que las vías electorales/representativas de participación tampoco funcionan del todo bien.

\section{Referencias bibliográficas}

Agüero, Alicia (2013): "Proyecto de Ley de Medidas Urgentes para reforzar la protección a los deudores hipotecarios”, en Revista CESCO de Derecho al Consumo, 5, pp. 262-272.

Aguiar de luQue, Luis (1977): Democracia directa y Derecho Constitucional. Madrid: EDERSA.

Almagro Castro, David (2016): “¿Qué iniciativa legislativa popular tenemos? ¿Qué iniciativa legislativa popular necesitamos? El art. 87.3 CE y la LOILP 4/2006 a debate", en Revista General de Derecho Constitucional, 22.

para las amas de casa sin otro empleo, hasta la situación actual en la que se encuentra en trámite desde una iniciativa ciudadana una Proposición de Ley sobre establecimiento de una prestación de ingresos mínimos en el ámbito de protección de la Seguridad Social. 
Aranda Álvarez, Elviro (2006): “La nueva Ley de iniciativa legislativa popular”, en Revista Española de Derecho Constitucional, 78, pp. 187-218.

Aragón, Manuel (1986): “La iniciativa legislativa”, en Revista Española de Derecho Constitucional, 16, pp. 287-312.

Astarloa Villena, Francisco (2002-2003): “La iniciativa legislativa popular en España”, Teoría y Realidad Constitucional, 10-11, pp. 273-231.

Biglino Campos, Paloma (1987): "La iniciativa legislativa popular en el Ordenamiento jurídico estatal”, en Revista Española de Derecho Constitucional, 19, pp. 75-130.

Cruz Villalón, Pedro (1980): "El referéndum consultivo como modelo de racionalización constitucional”, en Revista de Estudios Políticos, 13, pp. 145-168.

Cuesta López, Víctor (2008): Participación directa e iniciativa legislativa del ciudadano en democracia constitucional. Madrid: Thomson/Civitas.

FernÁndez Ferrero, Miguel Ángel (2001): La iniciativa legislativa popular. Madrid: Centro de Estudios Políticos y Consittucionales.

García Chourio, José (2009): “Instituciones de democracia directa: ampliando la receptibilidad estatal y control ciudadano sobre los gobiernos”, en Estudios Políticos, 35, pp. 181-208.

García-Escudero, Piedad (2009): La iniciativa legislativa del Gobierno. Madrid: Centro de Estudios Políticos y Constitucionales.

Marco Marco, Joaquín J. (2009): “La iniciativa legislativa popular en España (o el mito de Sisifo)", en Revista General de Derecho Constitucional, 8.

Morales Arroyo, José María (2017): “La democracia participativa como instrumento de impulso, deliberación y control”, “, en G. Ruiz-Rico Ruiz, A. Porras y M. Revenga (coord.): Regeneración democrática y reforma constitucional (Valencia: Tirant lo Blanch y Centro de Estudios Sociales y Jurídicos del Sur de Europa).

PÉREz SOLA, Nicolás (1994): La regulación constitucional del referéndum. Jaén: Universidad de Jaén.

Presno Linera, Miguel Ángel (2016<9: “La democracia participativa como instrumento de impulso, deliberación y control”, en José Luis Cascajo y Augusto de la Vega (Coord.): Participación, representación y democracia. Valencia: Tirant lo Blanch, pp. 201-234.

Punset, Ramón (1981): “Iniciativa legislativa popular y regional y fase introductoria del procedimiento legislativo", en Revista de Estudios Políticos, 22 (1981), pp. 213-226. 